\title{
Surgical repair of Vesico-Vaginal fistula: Vaginal route versus abdominal route.
}

1. MS (Urology)

Senior Registrar Urology and Kidney Transplantation

Pir Abdul Qadir Shah Jeelani Institute of Medical Sciences, Gambat.

2. FCPS (Urology)

Assistant Professor Urology and Kidney Transplantation

Pir Abdul Qadir Shah Jeelani Institute of Medical Sciences, Gambat.

3. FCPS (Pediatric Surgery) Assistant Professor Pediatric

Surgery

Pir Abdul Qadir Shah Jeelani Institute of Medical Sciences, Gambat.

Correspondence Address: Dr. Abdul Qayoom Khuhro Department of Urology and Kidney Transplantation

Pir Abdul Qadir Shah Jeelani Institute of Medical Sciences, Gambat. drshahidbhatt112@gmail.com

Article received on:

08/02/2021

Accepted for publication: 13/04/2021
Abdul Qayoom Khuhro', Muhammad Shahid Bhatti², Illahi Bux Brohi ${ }^{3}$

ABSTRACT... Objective: To determine outcomes and complications of vesico-vaginal fistula repair via vaginal and abdominal route. Study Design: Cross Sectional study. Setting: Department of Urology and Kidney Transplantation, Pir Abdul Qadir Institute of Medical Sciences Gambat. Period: January 2020 to December 2020. Material \& Methods: Patients having vesicovaginal fistula irrespective of age and fulfilling our inclusion criteria were included in the study using non-probability consecutive sampling technique. Patients having very large fistula, fistula involving neck of urinary bladder, failure of previous operation, patients with malignancy or co-morbidities were excluded from the study. Vaginal and abdominal approaches were used for fistula repair depending upon the level of fistula. Those operated via vaginal route were kept in trans-vaginal group and those operated via abdominal route were assigned trans-abdominal group. Results: Total 35 cases were studied having age 16-45 years with mean age of 32.6 \pm 4.2 years. Transvaginal fistula repair was done in $37.1 \%$ and transabdominal repair was done in $62.8 \%$ cases. Most common cause of VVF was previous gynecological surgery in $77 \%$ cases. Success rate was $100 \%$ in transvaginal fistula repair as compared to $95.4 \%$ success rate achieved in transabdominal repair of fistula. Conclusion: Trans abdominal and transvaginal route both are good approaches but Transvaginal route of fistula repair is associated with high success rate than transabdominal route with minimum complications and better outcomes but it needs expert surgeon.

Key words: $\quad$ Surgical Repair, Transabdominal Repair, Transvaginal Repair, Vesicovaginal Fistula.

Article Citation: Khuhro AQ, Bhatti MS, Brohi IB. Surgical repair of Vesico-Vaginal fistula: Vaginal route versus abdominal route. Professional Med J 2021; 28(11):1650-1655. https://doi.org/10.29309/TPMJ/2021.28.11.6411

\section{INTRODUCTION}

An abnormal communication between two or more epithelial surfaces is called fistula. According to an estimate three million women worldwide have untreated vesicovaginal fistula and most of them are in Asia and South Africa, while 30,000-130,000 cases are reported annually in Africa. ${ }^{1}$ Vesicovaginal fistula is an abnormal communication tract between urinary bladder and vagina causing involuntary dribbling of urine into vagina. ${ }^{2}$ Urinary incontinency, scalding and odor is troublesome for women and embarrassing. There are two main types of vesicovaginal fistula, congenital and acquired. Acquired fistula are divided into further subtypes like surgical, obstetrical, due to malignancy and post radiation therapy. ${ }^{3}$ In underdeveloped countries $>90 \%$ fistulas are due to obstetrical issues. ${ }^{4}$ In UK and other developed countries it is caused due to complications encountered in pelvic and gynecological surgeries. ${ }^{5}$ When vesicovaginal fistula is easily accessible and containing healthy tissue, it is called simple fistula. Fistula having difficult access, more tissue loss or involving ureteric orifices, is called complicated fistula. ${ }^{6}$

Its incidence, presentation and etiology is variable in different countries and in different regions of same country. ${ }^{7}$ First successful vesicovaginal fistula (VVF) repair was done by John Fatio in $1675 . .^{8}$ Sims (known as father of surgery) performed VVF repair in 1849 using sutures made of silver wire. ${ }^{9}$ James Marion introduced use of urinary bladder drainage catheter in fistula repair. ${ }^{10}$ Most of the times fistula occur in normal operative circumstances. It can be prevented by 
wide dissection of urinary bladder from vagina and cervix in correct plane and recognizing intraoperative bladder damage and proper repair meanwhile. There should be proper surgical exposure, adequate mobilization of vagina proper excision of fistula tract, tension free repair of urinary bladder and grafting is done when it is needed. ${ }^{11}$

\section{MATERIAL \& METHODS}

Sample size was calculated using WHO sample size calculator. Consecutive sampling technique was used for selection of the patients. Written consent was taken from all the cases in study group. Approval from ethical review board of the institution was taken as well. According to inclusion criteria patients having uncomplicated vesico-vaginal fistula isolated or with ureteric fistula, irrespective of age and cause of fistula, were included in this study. According to exclusion criteria those having very large fistula, or fistula involving urethra, urinary bladder neck or whole posterior wall of bladder who require urinary diversion were not included in this study.

Most of the patients with fistula developed after gynecological or obstetrical reasons presented with in one month to one year period after the event. There were three patients who were having this problem for more than five years. Patients in study group were admitted in the urology ward of study institute and all necessary baseline laboratory investigations as complete blood count, renal function tests, liver function tests, urine complete examination, ultrasonography of abdomen. Excretory urographic studies were done when ultrasonography showed hydro nephrosis or urinary obstruction of ureter. Cystoscopy of urinary bladder was done in every patient under intravenous sedation to see size and site of the fistula and speculum examination of vagina was also done meanwhile to see vaginal opening of fistula to plan route of repair of the fistula.

In case of ureteric obstruction or ureteric injury retrograde ureteric catheter was passed and retrograde urography was done to check correct placement of the catheter. In case of ureterovaginal fistula ureteric catheter was retained. Vaginal route of repair was used in those cases having vaginal opening of fistula at trigone or between bladder neck and trigone. Transabdominal route was used in case of large fistula defect or supra-trigonal opening seen on cystoscopy and in vaginal vault seen on speculum examination. Minimum time between fistula occurrence and surgical repair was six months and this wait was done to let fistula mature, for settling of inflammation and patient may recover from previous surgery. In abdominal repair, transperitoneal, trans-vesical approach was used. Extra-peritoneal trans-vesical approach was not used in any case. In all cases of VVF repair per urethra catheter and free drainage of cystostomy are very important in post-operative period.

Following the surgery vital signs monitoring done and input-output monitoring was done, intravenous fluid replacement, good antibiotic coverage and oral liquids were encouraged after the start of bowel movements. Vaginal packs were removed after 24 hours. In few patients urinary bladder irrigation was done 24-48 hours due to hematuria. Anticholinergic drugs were started in few patients to prevent spasm of urinary bladder. Cystostomy was clamped on $7^{\text {th }}$ post-operative day and removed after 10 days of surgery. Pelvic drains were removed after 48-72 hours after the surgery. After removal of the urethral catheter patients were monitored for 24-48 hours for any complaint. Follow-up was fortnightly for three months and then three monthly for a year.

\section{RESULTS}

Total 35 cases were divided into two groups. Those with low level fistula proximal to bladder neck, in $13(37.2 \%)$ cases, were placed in one group and trans-vaginal repair was done in these patients (trans-vaginal group). While other group was containing 22(62.8\%) cases with supra-trigonal (high) fistula and trans-abdominal repair of fistula was done in these cases (trans-abdominal group). In trans-abdominal group age distribution of the cases was as following, $5(22.7 \%)$ cases between $15-25$ years, $9(40.9 \%)$ cases between $26-35$ years and $8(36.4 \%)$ cases were between $36-45$ years of age with mean age of $32.6 \pm 4.2$ years. In transvaginal group $4(30.7 \%)$ cases were between 15 - 
25 years, 06(46.2\%) cases between 26-35 years and $03(23 \%)$ cases were having age $36-45$ years with mean age of $30.3 \pm 3.4$ years.

\begin{tabular}{|l|c|c|c|}
\hline Characteristics & $\begin{array}{c}\text { Trans- } \\
\text { vaginal } \\
\text { Group } \\
(\mathbf{n = 1 3}\end{array}$ & $\begin{array}{c}\text { Trans- } \\
\text { abdominal } \\
\text { Group } \\
(\mathbf{n = 2 2})\end{array}$ & $\begin{array}{c}\text { Total } \\
(\mathbf{n = 3 5 )}\end{array}$ \\
\hline Age (years) & $04(30.7 \%)$ & $05(22.7 \%)$ & $09(25.7 \%)$ \\
\hline $15-25$ & $06(46.2 \%)$ & $09(40.9 \%)$ & $15(42.8 \%)$ \\
\hline $26-35$ & $03(23 \%)$ & $08(36.4 \%)$ & $11(31.4 \%)$ \\
\hline $36-45$ & Etiology of Fistula \\
\hline $\begin{array}{l}\text { Trans-abdominal } \\
\text { hysterectomy }\end{array}$ & $08(61.5 \%)$ & $16(72.7 \%)$ & $24(68.6 \%)$ \\
\hline $\begin{array}{l}\text { Trans-vaginal } \\
\text { hysterectomy }\end{array}$ & $02(15.4 \%)$ & $01(4.5 \%)$ & $03(8.6 \%)$ \\
\hline Obstructed labor & $03(23 \%)$ & $05(22.7 \%)$ & $08(22.8 \%)$ \\
\hline
\end{tabular}

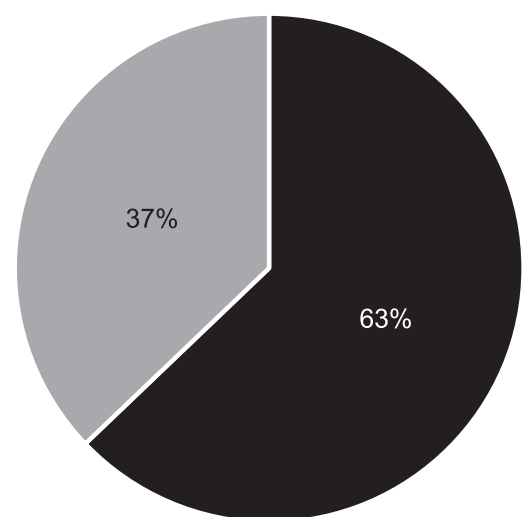

Transabdominal repair Transvaginal repair

Figure-1. Types of vesicovaginal fistula repair done in study group.

Etiology of VVF was transabdominal hysterectomy done previously in $24(68.5 \%)$ cases, transvaginal hysterectomy was done in $03(8.6 \%)$ and history of obstructed labor was present in 08(22.8\%) cases. Previous gynecological surgery was major cause of VVF among the patients. 07(20\%) cases were referred to our department for VVF repair after unsuccessful attempt of repair by gynecologists. 03(8.6\%) cases developed VVF after transabdominal hysterectomy in a tertiary care hospital, similarly $05(14.2 \%)$ cases developed VVF after transvaginal hysterectomy in tertiary care hospital.

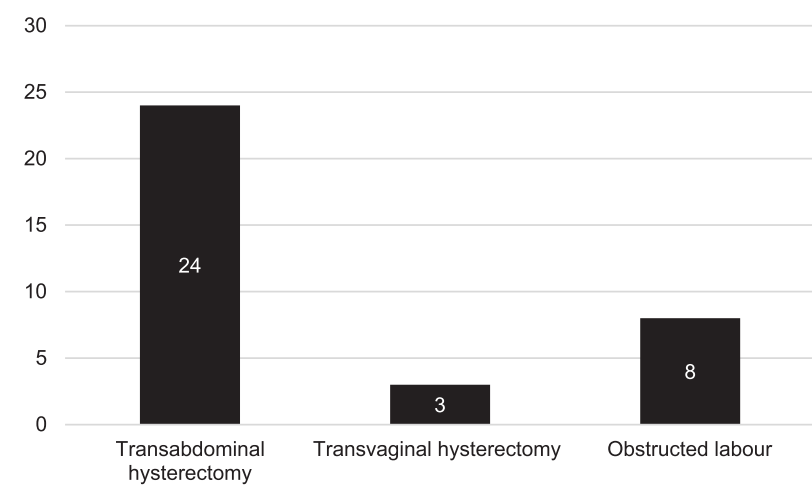

Figure-2. Causes of vesicovaginal fistula among the patients in study group.

Common postoperative complications reported after VVF repair were urinary bladder spasm and lower abdominal pain reported in $5(14.3 \%)$ and $4(11.4 \%)$ cases respectively. Mean duration of hospital stay was $3 \pm 1.5$ days. Mean duration of surgery was $65.4 \pm 15.7$ minutes.

\begin{tabular}{|c|c|c|c|}
\hline $\begin{array}{l}\text { Post-operative } \\
\text { Complications }\end{array}$ & $\begin{array}{c}\text { Transab- } \\
\text { dominal } \\
\text { Repair } \\
(\%=N / 35)\end{array}$ & $\begin{array}{c}\text { Trans- } \\
\text { vaginal } \\
\text { Repair } \\
(\%=\mathrm{N} / 35)\end{array}$ & P-Value \\
\hline Prolonged ileus & 03 (8.5\%) & $00(00 \%)$ & \multirow{5}{*}{$<0.01$} \\
\hline $\begin{array}{l}\text { Lower } \\
\text { abdominal pain }\end{array}$ & 04 (11.4\%) & 02 (5.7\%) & \\
\hline $\begin{array}{l}\text { Hematuria or } \\
\text { clot retention }\end{array}$ & 02 (5.7\%) & 01 (2.8\%) & \\
\hline $\begin{array}{l}\text { Urinary bladder } \\
\text { spasm }\end{array}$ & 05 (14.3\%) & 02 (5.7\%) & \\
\hline Recurrence & 01 (2.8\%) & 00 (00\%) & \\
\hline
\end{tabular}

In our study size of fistula was between $1-4 \mathrm{~cm}$. In most of the cases size of fistula was $>2 \mathrm{~cm}$. Success rate was $100 \%$ in transvaginal fistula repair as compared to $95.4 \%$ success rate achieved in transabdominal repair of fistula.

\section{DISCUSSION}

Prevalence of vesicovaginal fistula in developed countries is very rare but in developing and underdeveloped countries it is still very common. There is a huge number of cases in our country which are untreated. Gynecological or obstetric 
causes are very common risk factors of developing VVF in developing countries. Urinary bladder injury during gynecological surgeries or cesarean section is a common complication and often not treated well or sometimes missed or delayed treated. Obstructed labor is also an important risk factor of VVF. ${ }^{10,11}$ Ojewola et al did transabdominal repair of VVF and reported success rate of $92.1 \%$ among those undergoing first time repair and success rate was $95.6 \%$ among those having failed previous repair via transvaginal route. ${ }^{12}$ Bodner et al conducted study to see outcomes of VVF repair using transabdominal and transvaginal approaches and reported $97.8 \%$ success rate of vesico-vaginal fistula repair using transvaginal route while majority of the fistula (60\%) were simple, $36 \%$ were complex and $4 \%$ fistula were complicated in their study. ${ }^{13}$

A study conducted in Turkey by tatar et al in which VVF repair was done by transabdominal approach in 65\% cases, transvaginal approach used in $25 \%$ cases and laparoscopic repair was done in $10 \%$ cases. In their study major presenting complaint was urinary incontinence in $80 \%$ cases and constant leakage of urine from vagina in $20 \%$ cases and they concluded that vaginal route of repair should be first choice because it is associated with minimum complications. ${ }^{14}$ Malik et al stated that choice of route of repair depends on type and location of fistula and on the training and skills of the surgeon. ${ }^{15} \mathrm{~A}$ similar study conducted previously in Peshawar reported that in majority of cases cause of VVF was iatrogenic injury during hysterectomy in $67 \%$ cases while obstetric cause was found in 33\% cases. In their study $78 \%$ patients were having supra-trigonal fistula while $22 \%$ cases were having fistula at trigonal or infra trigonal level. ${ }^{16}$ In our study gynecological surgery was a major risk factor found in $68.5 \%$ cases and obstetric cause was found in $31.5 \%$ cases. Supra-trigonal (high) fistula was present in $22(62.8 \%)$ cases so Transabdominal repair of VVF was done while in 13(37.2\%) cases low level fistula was present proximal to bladder neck so transvaginal repair was done in these patients. A study conducted in India by Kumar et al included 58 patients and reported obstructed labor a cause of VVF in $68.96 \%$ cases while hysterectomy was cause of fistula in $29.31 \%$ cases and success rate of transvaginal route was $84.12 \%$ according to their results. ${ }^{17,18}$ These results are different from our study where gynecological etiology was main cause of VVF. In our study success rate was $100 \%$ in transvaginal repair of fistula.

A study conducted in Faisalabad by Ali et al reported obstetric fistulas in $66.7 \%$ and nonobstetric fistulas in $33.3 \%$ cases. They determined success rate of $93.3 \%$ by primary repair of VVF by Transabdominal and transvaginal route combined..$^{19}$ A study conducted in UK concluded that there is no difference in success rate of VF repair done via any one of two approaches transabdominal or transvaginal approach and transvaginal approach is more cost effective than transabdominal approach. ${ }^{20}$ Low level simple fistulas have high success rate than high level or complicated fistulas. Fistulas of large size are difficult to repair and have high recurrence rate. Skills of surgeon and developed setups play important role in outcomes of fistula repair. ${ }^{21}$

\section{CONCLUSION}

Gynecological etiology is a major cause of vesicovaginal fistula development in our community. Primary repair of fistula done via transabdominal or transvaginal approach has great outcomes but transvaginal route has higher success rate and less complications than transabdominal route.

\section{Copyright $@ 13$ Apr, 2021.}

\section{REFERENCES}

1. El-Azab AS, Abolella HA, Farouk M. Update on vesicovaginal fistula: A systematic review. Arab journal of urology. 2019 Jan 2; 17(1):61-8.https://doi.or $\mathrm{g} / 10.1080 / 2090598 X .2019 .1590033$.

2. Özkaya F, Cinislioğlu AE, Aksoy Y, Adanur Ş, Yılmaz EP, Polat Ö et al. Vesicovaginal fistula repair experiences in a single center high volume of 33 years and necessity of cystostomy. Turkish Journal of Urology. 2021 Jan; 47(1):66.https://doi.org/10.1080/01443615.2 017.1407301 .

3. Rajaian S, Pragatheeswarane M, Panda A. Vesicovaginal fistula: Review and recent trends. Indian Journal of Urology: IJU: Journal of the Urological Society of India. 2019 Oct; 35(4):250. https://dx.doi.org/10.4103\%2Fiju. IJU_147_19. 
4. Kopp DM, Bengtson AM, Tang JH, Chipungu E, Moyo $\mathrm{M}$, Wilkinson $\mathrm{J}$. Use of a postoperative pad test to identify continence status in women after obstetric vesicovaginal fistula repair: A prospective cohort study. BJOG: An International Journal of Obstetrics \& Gynaecology. 2017 May; 124(6):966-72. https://doi. org/10.1111/1471-0528.14505.

5. Pope R, Ganesh P, Chalamanda C, Nundwe W, Wilkinson $J$. Sexual function before and after vesicovaginal fistula repair. The journal of sexual medicine. 2018 Aug 1; 15(8):1125-32. https://doi.org/10.1016/j. jsxm.2018.06.006.

6. Kanao H, Aoki Y, Hisa T, Takeshima N. Total laparoscopic pelvic exenteration for a laterally recurrent cervical carcinoma with a vesicovaginal fistula that developed after concurrent chemo radiotherapy. Gynecologic Oncology. 2017 Aug 1; 146(2):438-9. https://doi. org/10.1016/j.ygyno.2017.05.030.

7. Lee D, Zimmern P. Vaginal approach to vesicovaginal fistula. The Urologic clinics of North America. 2019 Feb; 46(1):123. https://doi.org/10.1016/j.ucl.2018.08.010.

8. Moses RA, Gormley EA. State of the art for treatment of vesicovaginal fistula. Current Urology Reports. 2017 Aug 1; 18(8):60. https://doi.org/10.1007/s11934017-0708-5.

9. McKay E, Watts K, Abraham N. Abdominal approach to vesicovaginal fistula. Urologic Clinics of North America. 2019 Feb 1; 46(1):135-46.

10. Bora GS, Singh S, Mavuduru RS, Devana SK, Kumar S, Mete UK, Singh SK, Mandal AK. Robot-assisted vesicovaginal fistula repair: A safe and feasible technique. International Urogynecology Journal. 2017 Jun $1 ;$ 28(6):957-62. https://doi.org/10.1007/s00192016-3194-2.

11. Tewary SK, Das RK, Choudhary A, Basu S, Dey RK. Modified technique of doubly folded peritoneal flap interposition in transabdominal vesicovaginal fistula repair: Our experience of 36 cases. Urologia Internationalis. 2020; 104(11-12):928-32. https://doi. org/10.1159/000509446.

12. Ojewola RW, Tijani $\mathrm{KH}$, Jeje EA, Ogunjimi MA, Animashaun EA, Akanmu ON. Transabdominal Repair of Vesicovaginal Fistulae: A 10-Year Tertiary Care Hospital Experience in Nigeria. https://ir.unilag.edu. ng/handle/123456789/7796.
13. Bodner-Adler B, Hanzal E, Pablik E, Koelbl H, Bodner $\mathrm{K}$. Management of vesicovaginal fistulas (VVFs) in women following benign gynaecologic surgery: A systematic review and meta-analysis. PloS one. 2017 Feb 22; 12(2):e0171554. https://doi.org/10.1371/ journal.pone. 0171554 .

14. Tatar B, Oksay T, Cebe FS, Soyupek S, Erdemoğlu E. Management of vesicovaginal fistulas after gynecologic surgery. Turkish journal of obstetrics and gynecology. 2017 Mar; 14(1):45.

15. Malik MA, Sohail M, Malik MT, Khalid N, Akram A. Changing trends in the etiology and management of vesicovaginal fistula. International Journal of Urology. 2018 Jan; 25(1):25-9. https://doi.org/10.1111/iju.13419.

16. Naeem M, Shamsher S, Ullah I, Ullah R, Khan RA, Gul B. Etiology and outcome of vesicovaginal fistulae surgical repair, an experience of 58 cases at institute of kidney diseases Hayatabad, Peshawar. KJMS. 2018 May; 11(2):212.

17. Kumar M, Agarwal S, Goel A, Sharma A, Agarwal A, Pandey S, Sankhwar SN. Transvaginal repair of vesico vaginal fistula: a 10-year experience with analysis of factors affecting outcomes. Urologia internationalis. 2019; 103(2):218-22. https://doi. org/10.1159/000499411.

18. Pattinama N, Hardianto G. Comparison the success rate of vesicovaginal fistula repair surgical with transvaginal and trans abdominal procedure: Metaanalysis. Medical and Health Science Journal. 2020 Aug 28; 4(2):109-15.

19. Ali R, Niaz G, Ehsan R. Vesicovaginal Fistula (VVF): Success of primary repair. The Professional Medical Journal. 2019 Dec 10; 26(12):2090-4. https://doi. org/10.29309/TPMJ/2019.26.12.3131.

20. Warner R, Beardmore-Gray A, Pakzad M, Hamid R, Ockrim J, Greenwell T. The cost effectiveness of vaginal versus abdominal repair of vesicovaginal fistulae. International urogynecology journal. $2019 \mathrm{Jul}$ 18:1-7.

21. Jadav RR, Manjuprasad GB. An outcome of the management of vesico-vaginal fistula: experience at KIMS, Hubli, Karnataka, India. International Surgery Journal. 2019 Jan 28; 6(2):552-6. https://dx.doi. org/10.18203/2349-2902.isj20190402. 


\section{AUTHORSHIP AND CONTRIBUTION DECLARATION}

\begin{tabular}{|c|l|l|l|}
\hline No. & \multicolumn{1}{|c|}{ Author(s) Full Name } & \multicolumn{1}{|c|}{ Contribution to the paper } & Author(s) Signature \\
\hline 1 & Abdul Qayoom Khuhro & $\begin{array}{l}\text { Data analysis, Data } \\
\text { collection, Data analysis. } \\
\text { Topic selection and data } \\
\text { collection, Abstract and } \\
\text { recording. } \\
\text { Data analysis, Data } \\
\text { collection, Found additional } \\
\text { literature for information, Data } \\
\text { composing. }\end{array}$ \\
\hline 3 & M. Shahid Bhatti & \\
\hline
\end{tabular}

